That kind of argument always pulls in

Emotion is unavoidable in this kind of debate, and your readers will no doubt discern a smidgin of it in this letter. But in science, emotion should be the engine and reason should hold the steering-wheel and press the accelerator and brake. Risk analysis quite properly helps to guide the foot between those rival pedals. Robert CAHN

The University of Sussex,

School of Engineering and

Applied Science.

We did not wish to imply that emotional commitment characterised only one side of the nuclear debate-far from it-only that it was impossible to assess risks without taking such factors seriously. Further, the unknown risk referred to was the risk of failure of a commercial scale fast breeder reactor, for which there is no experience.-Ed.

\section{Solar activity and influenza}

SIR.-I would like to elaborate further on the remarkable correlation between influenza A viral antigenic shifts and peaks of the sunspot cycle as noted by R. E. Hope-Simpson (Nature 275, 86; 1978)

Ancient "cosmic and telluric theories" regarding influenza epidemics date as far back as the time of Hippocrates

(Thomson, D. \& Thomson, R. Ann. Pickett-Thomson Res. Lab. 9, 257-261; 1933 and 10,1125-1140;1934). Over half a century ago, F. G. Crookshank (Mil. Surg. 59, 284-290; 1926) defended the hypothesis that influenza pandemics and solar activity were correlated, and this possible relationship was further studied by M. Mygge (Acta Med. Scand. suppl. XXXII, 105-134; 1930). Since the discovery of a filtrable virus as the aetiological agent of influenza in the 1930s, the notion of a solar-influenza association has been largely dismissed and forgotten.

Except for the pandemic of 1889 , the beginning dates of historical influenza pandemics in the 18th and 19th centuries (Mote, J. R. In: Viral and Rickettsial Diseases, Harvard University Press, 257-261, 1933), as well as pandemics and viral antigenic shifts in this century (Kilbourne, E. D. J. Amer. Med. Assoc. $237,1225-1228$; 1977), appear to have occurred in years of high sunspot number. From our present knowledge of influenza. it is not unreasonable to assume that these severe historical pandemics spreading rapidly to world-wide proportions were associated with major shifts in the influenza A haemagglutinin $(\mathrm{H})$ and neuraminidase $(\mathrm{N})$ surface antigens.

The mechanisms on how the solar cycle two directions.

can affect influenza pandemics may only be speculated upon at this time. The amount of ultraviolet light incident on the surface of the earth is increased in vears of high sunspot activity (Pettit, P. A strophys. J. 75, 185-221; 1932), and this can conceivably accelerate the mutation rate of the influenza virus. The relationship between long-term cyclical fluctuations in meteorological and climatic conditions with the sunspot cvcle remains controversial at this time. It is plausible, nevertheless, that during years of high solar activity. a more favourable ecological environment may exist for the genetic recombination of human and animal influenza viruses, with the emergence of new pandemic strains.

It is interesting to note that while the swine influenza virus (HswlNl) reappeared in 1976, its spread into pandemic or even epidemic proportions did not occur in this year of sunspot minimum. The resurfacing of the HINl subtype ("Russian flu") in December of 1977 was completely unexpected. The sunspot cycle was beginning its rapid ascent at that time.

It would not at all be surprising if a new strain of influenza A virus should emerge and dominate in the sunspot maximum vears of the near future. On the other hand, perhaps what could only be expected from the elusive influenza virus is the unexpected.

US Public Health Service Hospital RoY ING Baltimore, Md, USA

\section{Seveso: premature optimism}

SIR,--At the recent Seventh International Congress of Pharmacology in Paris, Dr G. Reggiani of the Hoffman-La Roche Medical Board presented a communication on the clinical features of the July 1976 TCDD accident in Seveso.

The Mario Negri Institute have closely followed many aspects of the investigations since then, and we feel some comment is necessary.

TCDD $(2,3,7,8$ tetrachlorodibenzo-pdioxine) is one of the most

powerful known toxic chemicals in animals, especially as regards its cumulative and delayed effects. So there cannot but be serious concern about the long term effects of the accident on man. regardless of the present impossibility of making any defensible prognosis

(S. Garattini Biomedicine 26, 28-29; 1977).

Since the accident, Hoff man-La Roche, which owns ICMESA through its subsidiary Givoudan, has been faced with many problems, of which public relations is certainly not the least. Its representatives have with every right denied false or exaggerated press reports such as charges that ICMESA had been secretly engaged in manufacturing

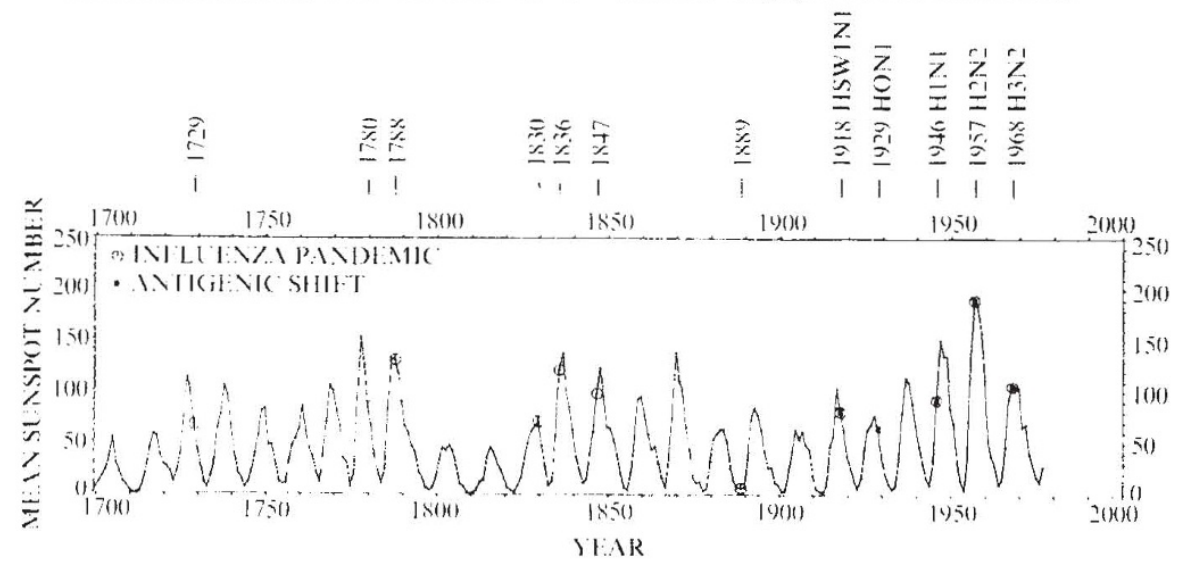

warfare chemicals. After a while, though they began to comment optimistically on the potential health risks to people living in the polluted area. For example. Dr Reggiani noted that: "In the case of TCDD man seems to respond to a certain extent differently from other animal species ..." (J. Walsh Science 197, $1064-1067$; 1977). There is no question that all efforts to minimise exposure of the residents in the disaster area should not be discontinued and we fervently hope Dr Reggiani's opinion proves right. But he seems to be rushing it somewhat by extending his increasingly sanguine attitude to retrospective evaluation.

His Paris communication was obviously biased by his desire to make little of the possible damage to human health. Thus he offered reassuring interpretations of findings such as those on chloracne, the typical skin lesion after TCDD exposure in humans, pointing out its "quick healing tendency" with the unsupported implication that it was quantitatively linked to exposure. He failed to mention its recurrence in people from widely scattered areas. Regardless of whether they were based on poorly reliable data such as observed rates of spontaneous abortion. Dr Reggiani confidently presented negative findings as strong evidence for the absence of TCDD induced pathology, with no criticism of the epidemiological methodology adopted or related problems deriving from the lack of adequate historical controls.

These points are evident from his abstract in the official volume (Abstract $n$ 2890, 953) which concludes: "The measures of protection of the population and prevention of further damage carried out at our request by the local authorities have avoided the severe injuries observed in previous similar accidents".

In view of this statement we must recall that the Seveso case cannot be compared with any previous accident involving TCDD because of 1) the uprecedently heavy contamination of inhabited areas. 2) the delay in recognising the nature of the accident and the resulting lag before protective measures were adopted, and 3) the significant amounts of TCDD persisting in the environment where people live. No mention of the TCDD risk was made to the local authorities before the disaster and even after it. Roche took almost two weeks to admit that TCDD had escaped from the plant.

It is unfortunate when someone takes advantage of a scientific meeting to present such misleading statements. People with no knowledge of the background and complexity of the Seveso case and the difficulty of epidemiological studies, may be led to accept the idea that thanks to Roche, all is well in Seveso now. This sounds outrageous to those who have already suffered distress from the disaster, apart from all considerations of feared future effects on health, which only time will reveal.

In addition and perhaps most relevant. our concern about Dr Reggiani's statement is of practical value. Everybody knows how difficult it is to motivate people to keep coming back for the controls needed for epidemiological studies. If the idea is spread around that there are no risks it will be difficult to collect long term data. No data available may well represent the best possible proof that no toxic effects occurred!

\section{Manara, S. Garattini}

Istituto di Ricerche Farmacologiche "Mario Negri", Milan, Italy 